\title{
Improve the Productivity of Welding and Cutting Steel Pipe by using A New Fixture
}

\author{
Nguyen Van Chuong \\ University of Technology and Education- \\ The University of Danang
}

\begin{abstract}
Through field survey, analysis of the characteristics and scope of application of various types of pipe cutting and cutting parts, the article proposed a new device to serve welding, Automatic cutting with medium capacity. After selecting and calculating the geometrical parameters of the main parts of the machine, the experimental model of this new fixture was developed. Highly reliable workmanship, the products created by the support of this device are of high quality, the machine structure can be moved easily on the site. The device worked well with low cost and easy operation. From there, it can be put into use in the factory or mechanical workshop in the field of welding and cutting tube details with medium capacity.
\end{abstract}

Key words - Fixture; welding and cutting; steel tube; design; manufacturing.

\section{INTRODUCTION}

The fixture in mechanical processing plays an important role in the quality of the product in the manufacturing process. In the fixture group, the weld-cutting fixture has a simpler structure and should be improved. The only thing more critical to welding success than good fixturing is a good welder. For welds more complex than joining planar surfaces, welding fixtures help welders ensure that they're joining the right things together in the right locations. Conventional welding fixtures tend to fall into three categories - expensive machined components, uncustomized modular fixturing, and hacked-together solutions. Each of these has its own downside: machined fixtures are effective but expensive to produce, modular fixtures are cheap but difficult to assemble, and hacked-together solutions produce poor welds far more often than successful ones.

In mechanical processing, the cutting of long tube embryo into short embryo or the fitting as well as the welding of the short tube embryos ... is quite frequent. To ensure the accuracy of size, shape ... as required as well as high productivity, it is necessary to use the fixture. This article has studied the design and the manufacturing of automatic welding and cutting fixture for steel tubes with medium capacity. The fixture after complete manufacturing has been working reliably, the products made with the help of this device have high quality, compact machine structure that can be easily moved on site, highly usable, low cost and easy to operate. Finally, this device can be used in factories or mechanical processing facilities in welding and cutting.

At present, there are many types of fixtures for welding and cutting pipe parts, including ZT [1] series welding tool with high capacity, load capacity from 5 - 40 tons, diameter from 600 - $5200 \mathrm{~mm}$; or the rotary Positoner HB [2], with a capacity of less than $300 \mathrm{~kg}$, a maximum diameter of $300 \mathrm{~mm}$. However, in the segment of medium capacity, the appearance of welding and cutting equipment for pipes with diameter 300 - $600 \mathrm{~mm}$ is quite small. Therefore, the article has researched the design and manufacture of welding and cutting equipment for medium-sized pipes. After workmanship, reliable and compact workpieces can be moved flexibly on site, which can be used in workshops or mechanical workplaces in welding and cutting.

\section{RESEARCH OBJECTIVES}

\subsection{Technological capabilities of device}

Based on the scope of study, the requirement is to perform the welding or cutting a pipe with the technical parameters as follows:

- Length: $\mathrm{L}_{\max }=6000 \mathrm{~mm}$;

- Maximum diameter: $\mathrm{D}_{\max }=600 \mathrm{~mm}$;

- Minimum diameter: $\mathrm{D}_{\min }=200 \mathrm{~mm}$;

- Thickness: $\mathrm{S}_{\max }=16 \mathrm{~mm}$;

- Volume: $\mathrm{P}_{\max }=1420 \mathrm{Kg}$.

For the required pipe size, weld or cross section by rotating the tube by direct drive from the accelerator motor will reduce vibration due to low rotational speed, as shown in Figure 1, pipe clamped directly from the chuck of the center while rotation will be concentric, resulting in the maintenance of the arc clearance or cutting head distance to the surface welding, cutting always keep distance to welding mode, cutting more stable. Thus, this option allows the possibility of improving the quality of the welding line or cutting line is always guaranteed. Using this method, the structure becomes simple, neat and easy to move in moving position.

With a diameter of $200 \div 600 \mathrm{~mm}$, there are many clamping options, but for clamping as well as removing the embryo quickly, and can be used easily, easy to find on the market, the option of clamping with a tray 3-pin selfcentering clamps [4] will become more suitable, as shown in Figure 2 .

In addition, with this option, it is easy to set up additional rotation planes for welding, cutting in various angles, which increases the workability of fixtures such as welding, cutting details at various positions within the range from $0^{\circ} \div 90^{\circ}$.

With pipe diameters in the range of $200 \div 600 \mathrm{~mm}$, there are many ways of clamping, but for clamping as well as 
removing the embryo quickly, and can be used easily, easy to find on the market, select. Choosing a 3-pin self-centering clamp [4] will become more suitable, as shown in Figure 2.

The design of the fixture for the fixture must meet certain requirements such as:

+ The overall structure of the fixture must be neat.

+ When moving motion work must be smooth, no vibration.

+The transmitter must change the angle of work simultaneously with the clamping wheel to make the angle of welding, cutting from $0^{\circ} \div 90^{\circ}$.

+ Response rate working output of chuck $(0.1 \div$ $1 \mathrm{~m} /$ minute).

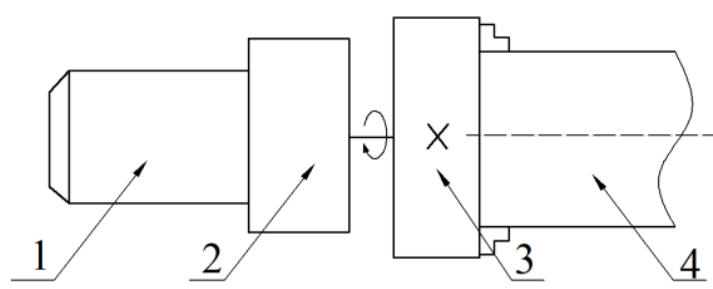

Figure 1. Tube rotation

1-engine; 2-speed gear box; 3-Clamp mechanism; 4- Tube

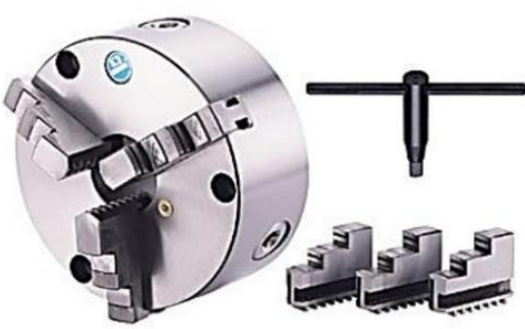

Figure 2. 3-spoke chuck

Table 1. Basic Parameters of Cycloid Gear

\begin{tabular}{|c|c|c|c|c|c|}
\hline $\begin{array}{c}\text { Numbe } \\
\mathrm{r} \text { of } \\
\text { teeth } \\
\mathrm{Z}_{\mathrm{c}}\end{array}$ & $\begin{array}{c}\text { Eccen } \\
\text { tricity } \\
\mathrm{a}\end{array}$ & $\begin{array}{c}\text { Radius of the } \\
\text { circle through } \\
\text { the center of the } \\
\text { rollers of the } \\
\text { pinch teeth } \\
\mathrm{r}_{\mathrm{p}}\end{array}$ & $\begin{array}{c}\text { The } \\
\text { diameter of } \\
\text { the rollers } \\
\text { on the pinch } \\
\text { teeth } \\
\mathrm{d}_{\mathrm{rp}}\end{array}$ & $\begin{array}{c}\text { The } \\
\text { diameter of } \\
\text { the pin on } \\
\text { the pin } \\
\mathrm{d}_{\mathrm{sp}}\end{array}$ & $\begin{array}{c}\text { Width of } \\
\text { cycloid } \\
\text { gearsb }\end{array}$ \\
\hline 19 & 4 & 150 & 26 & 20 & 15 \\
\hline
\end{tabular}

Table 2. Geometry of Cycloid Gears (mm)

\begin{tabular}{|c|c|c|c|c|c|c|}
\hline $\begin{array}{c}\text { The } \\
\text { diameter } \\
\text { of the } \\
\text { cycloid } \\
\text { gears } \\
\mathrm{d}_{\mathrm{fc}}\end{array}$ & $\begin{array}{c}\text { Maximum } \\
\text { diameter } \\
\text { cycloid gear } \\
\mathrm{d}_{\mathrm{ac}}\end{array}$ & $\begin{array}{c}\text { High of } \\
\text { teeth } \mathrm{h}\end{array}$ & $\begin{array}{c}\text { The } \\
\text { diameter } \\
\text { of the } \\
\text { latch } \\
\text { holes } \mathrm{D}_{\mathrm{w}}\end{array}$ & $\begin{array}{c}\text { The } \\
\text { latch } \\
\text { size } \mathrm{d}_{\mathrm{sw}}\end{array}$ & $\begin{array}{c}\text { Diameter } \\
\text { rollers } \\
\text { latch out } \\
\mathrm{d}_{\mathrm{rw}}\end{array}$ & $\begin{array}{c}\text { The } \\
\text { diameter } \\
\text { of the } \\
\text { latch } \\
\text { hole } \mathrm{d}_{\mathrm{w}}\end{array}$ \\
\hline 230 & 246 & 8 & 145 & 16 & 30 & 38 \\
\hline
\end{tabular}

Thus, in order to meet the requirements set forth, it is necessary to use a deceleration motor to establish the source of the work of the fixture. Based on the original data, the DK42-6 engine was selected with $\mathrm{N}_{\text {đc }}=1,7(\mathrm{kw})$ and rotation $=925 \mathrm{r} /$ minute [3]. In addition, the working speed of the clamping plate is small, resulting in a gear ratio of 370 .
For gear motors with large transmission ratios, many measures can be used to reduce the speed, such as the use of planetary gear reducer or can also use Cycloid gear reducer (set gear wheel transmission). In this part, the author recommends the use of a cycloid gear transmission because the joint characteristics of this type of transmission have no gap next to the teeth so work smoothly, do not cause collisions when reversing rotation, gear transmission Cycloid teeth have a compact structure, light weight, high transmission ratio, high transmission efficiency, high load capacity, center shaft and center shaft are all in a straight line (coaxial) such large transmissions, proceed to design the gearbox 2 gear reducer cycloid as shown in Figure 3.

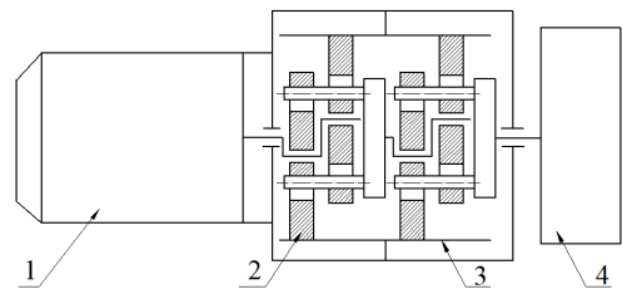

(a)

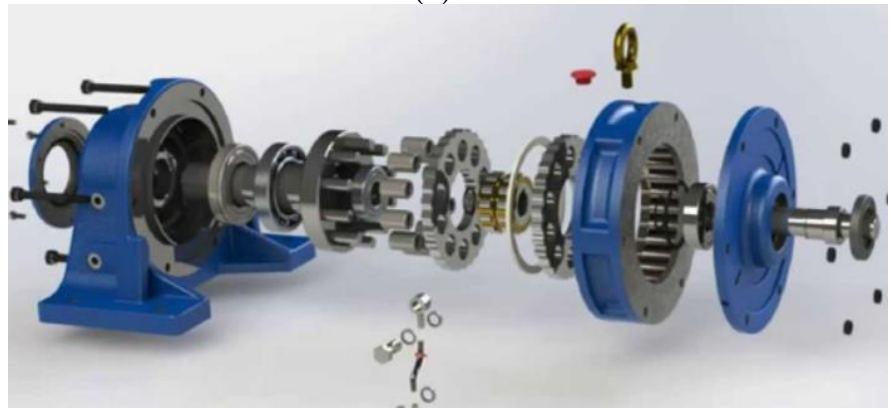

(b)

Figure 3. Diagram of the main working principle 1-engine; 2-cycloid gear; 3-pin latch; 4-chuck (a); the structure of the Cycloid gear box
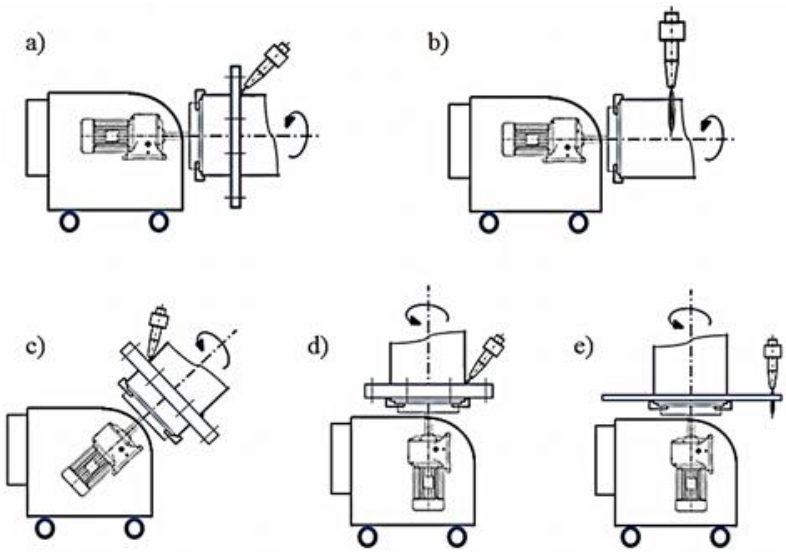

Figure 4. Working angles of the work structure

a) Welding corners in position by horizontal; b) Horizontal cutting; c) Welding corners in position by 45 degrees on a sloping; $d$ ) Welding corners in position by vertically; e) Cut in the vertical position

Distributed transmission rates for fast and slow levels:

$$
i_{n h}=i_{c h}=\sqrt{370}=19
$$

In order to minimize the production of many different sizes of cycloid gears, and to provide a compact structure for the gearbox, the author designs slow- same. 
In fact, in welding and cutting, we often encounter tubular or circular details such as flanges, flywheels, etc. From the specific requirements of machining, machine elements can be made from welding, horizontal cutting. This elements was done vertically or at any angle in the range from $0^{\circ} \div 90^{\circ}$.

The scope of the article goes into extensive research and creates an integrated fixture for conducting welding and cutting of parts in various locations to meet a number of requirements as outlined above, was shown in Figure 4.

Notice that the rotation angle control via the deceleration motor using the magnetic brake is consistent with the characteristics, texture and general working principle of the fixture.

Based on the original data, DK51-6 engine selection with $\mathrm{Ndc}=2.8(\mathrm{kw})$ and $\mathrm{nd}$ rotation $=950 \mathrm{r} /$ minute [3]. In addition, geometric parameters of fast-acting cycloid gears are calculated as shown in Table 3 and Table 4.

Table 3. Basic Parameters of Cycloid Gear

\begin{tabular}{|c|c|c|c|c|c|}
\hline $\begin{array}{c}\text { Numbe } \\
\mathrm{r} \text { of } \\
\text { teeth } \\
\mathrm{Z}_{\mathrm{c}}\end{array}$ & $\begin{array}{c}\text { Eccen } \\
\text { tricity } \\
\mathrm{a}\end{array}$ & $\begin{array}{c}\text { Radius of the } \\
\text { circle through } \\
\text { the center of the } \\
\text { rollers of the } \\
\text { pinch teeth } \\
\mathrm{r}_{\mathrm{p}}\end{array}$ & $\begin{array}{c}\text { The } \\
\text { diameter of } \\
\text { the rollers } \\
\text { on the pinch } \\
\text { teeth } \\
\mathrm{d}_{\mathrm{rp}}\end{array}$ & $\begin{array}{c}\text { The } \\
\text { diameter of } \\
\text { the pin on } \\
\text { the pin } \\
\mathrm{d}_{\mathrm{sp}}\end{array}$ & $\begin{array}{c}\text { Width of } \\
\text { cycloid } \\
\text { gearsb }\end{array}$ \\
\hline 31 & 2 & 80 & 16 & 8 & 8 \\
\hline
\end{tabular}

Table 4. Geometry of Cycloid Gears (mm)

\begin{tabular}{|c|c|c|c|c|c|c|}
\hline $\begin{array}{c}\text { The } \\
\text { diameter } \\
\text { of the } \\
\text { cycloid } \\
\text { gears } \\
\mathrm{d}_{\mathrm{fc}}\end{array}$ & $\begin{array}{c}\text { Maximum } \\
\text { diameter } \\
\text { cycloid gear } \\
\mathrm{d}_{\mathrm{ac}}\end{array}$ & $\begin{array}{c}\text { High of } \\
\text { teeth } \mathrm{h}\end{array}$ & $\begin{array}{c}\text { The } \\
\text { diameter } \\
\text { of the } \\
\text { latch } \\
\text { holes } \mathrm{D}_{\mathrm{w}}\end{array}$ & $\begin{array}{c}\text { The } \\
\text { latch } \\
\text { size } \mathrm{d}_{\mathrm{sw}}\end{array}$ & $\begin{array}{c}\text { Diameter } \\
\text { rollers } \\
\text { latch out } \\
\mathrm{d}_{\mathrm{rw}}\end{array}$ & $\begin{array}{c}\text { The } \\
\text { diameter } \\
\text { of the } \\
\text { latch } \\
\text { hole } \mathrm{d}_{\mathrm{w}}\end{array}$ \\
\hline 140 & 148 & 4 & 90 & 10 & 20 & 24 \\
\hline
\end{tabular}

After calculating the parameters of the transmission gear cone level slow as follows:

+ Roller cone module: $\mathrm{ms}=1.5 \mathrm{~mm}$

+ Hat length: $\mathrm{L}=75 \mathrm{~mm}$

+ Corner fitting:

+ Roller cone angle (dividing cone): $1=15 \mathrm{o} ; 2=74 \mathrm{o}$

+ Roller diameter (split ring):

$\mathrm{d} 1=33 \mathrm{~mm} ; \mathrm{d} 2=165 \mathrm{~mm}$

+ Top ring diameter:

De1 $=36 \mathrm{~mm}$; De2 = $166 \mathrm{~mm}$

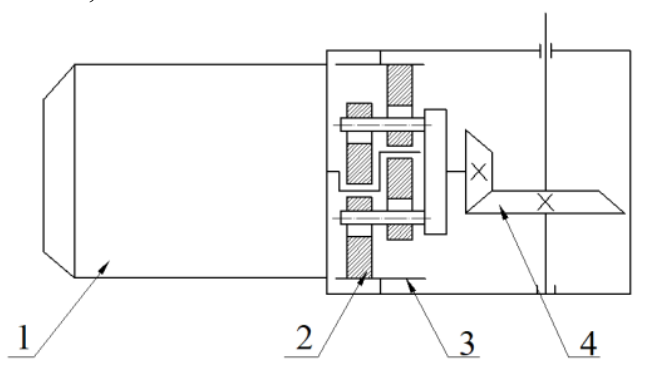

Figure 5. Principle of transmission control rotation angle 1-engine; 2-cycloid gear; 3-pin latch; 4-Cone gear

\subsection{Adjust engine speed}

A variable-frequency drive (VFD; also termed adjustablefrequency drive, "variable-voltage/variable-frequency drive", variable speed drive, AC drive, micro drive or inverter drive) is a type of adjustable-speed drive used in electro-mechanical drive systems to control AC motor speed and torque by varying motor input frequency and voltage.

VFDs are used in applications ranging from small appliances to large compressors. About $25 \%$ of the world's electrical energy is consumed by electric motors in industrial applications, which can be more efficient when using VFDs in centrifugal load service, however, VFDs' global market penetration for all applications is relatively small.

Over the last four decades, power electronics technology has reduced VFD cost and size and has improved performance through advances in semiconductor switching devices, drive topologies, simulation and control techniques, and control hardware and software.

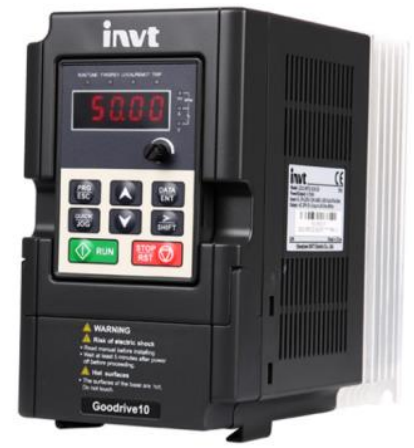

(a)
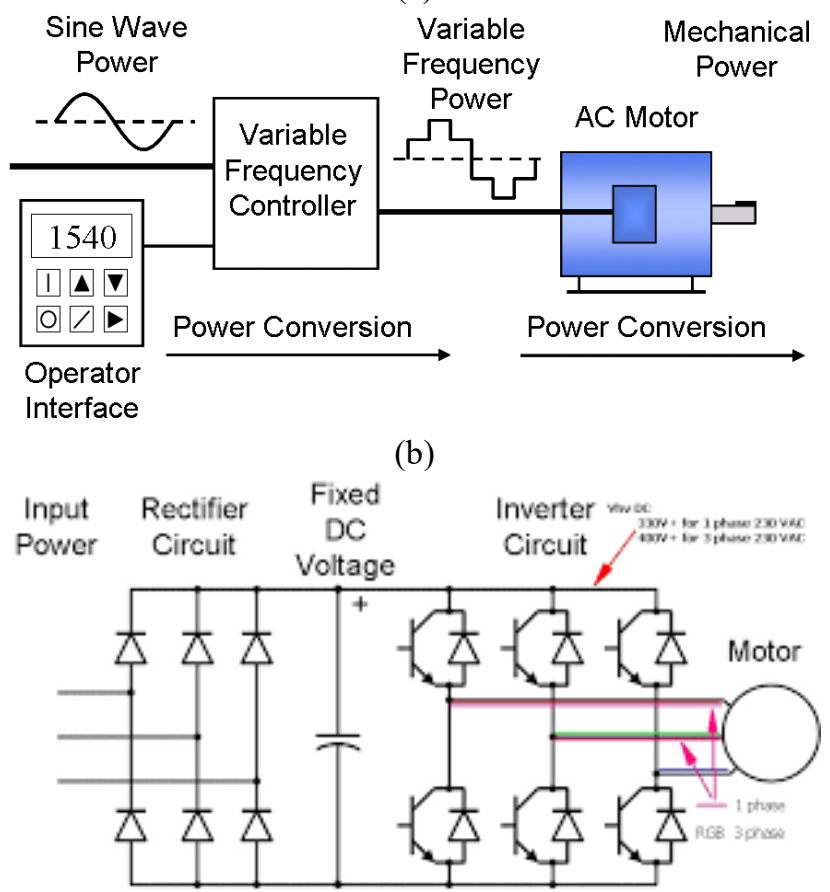

(c)

Figure 6. Inverter Invt Goodrive 10 (a), VFD system (b), (c) the main circuit

The difference between the welded fittings, the pipeshaped parts compared to the welded fittings, the cut-offs in straight lines on the same flat surface: details that may vary in diameter. So when doing the welding, cutting each part 
corresponding to that there is a change in the rotational speed of the work mechanism. If you look at welding conditions, cut a piece of the same thickness but different in diameter, in this case, the larger the diameter, the smaller the rotation speed and vice versa. Welding velocity is the conventional ( $\mathrm{m} /$ minute; $\mathrm{mm} /$ minute).

So for deceleration motors, the calculation of engine power as well as the output velocity is only done once. If the transmission ratio is greater then that means that the size and mass of the engine will increase, the investment cost will be high. On the other hand, the output velocity is only fixed at a value.

Based on the engine speed reduction methods mentioned above. To meet the task requirements of the subject, the method of changing the speed of the engine through frequency change is still the solution has more advantages than the whole, as shown in Figure 6.

The most special feature of the inverter drive system - the motor is able to adjust the speed of the engine. That is through adjusting the frequency and can adjust the motor speed to vary as desired in a wide range.

Using inverters, it also means implicitly enjoying a lot of smart, flexible features such as auto-recognition engine; control over the network; can set up 16 speed levels; control the engine start currents so that the soft startup process improves the mechanical strength of the engine; minimizing installation, maintenance costs; space saving installation; energy saving modes, ...

When using the inverter there will be no fears about not being able to control the transmission power because we can control it through overload, overheat protection. current, over voltage, low voltage, phase loss, phase difference ... of inverte

\section{RESULTS AND DISCUSSION}

\subsection{Experiment model of welding, cutting}
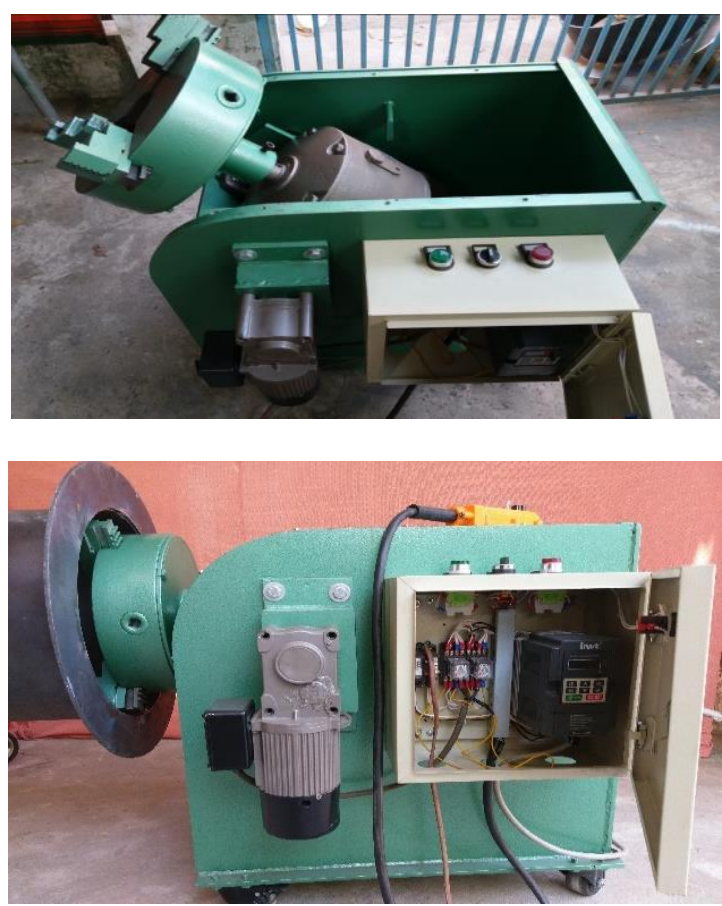

Figure 7. Experimental model

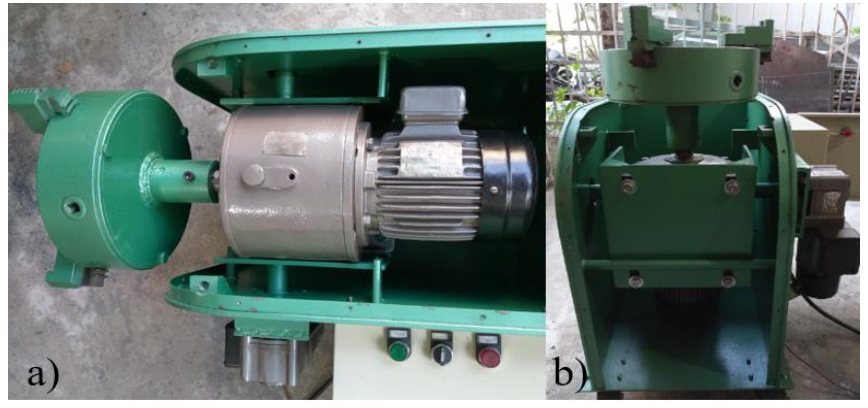

Figure 8. Structure of actuators

a. Main actuator b. Drive angle control
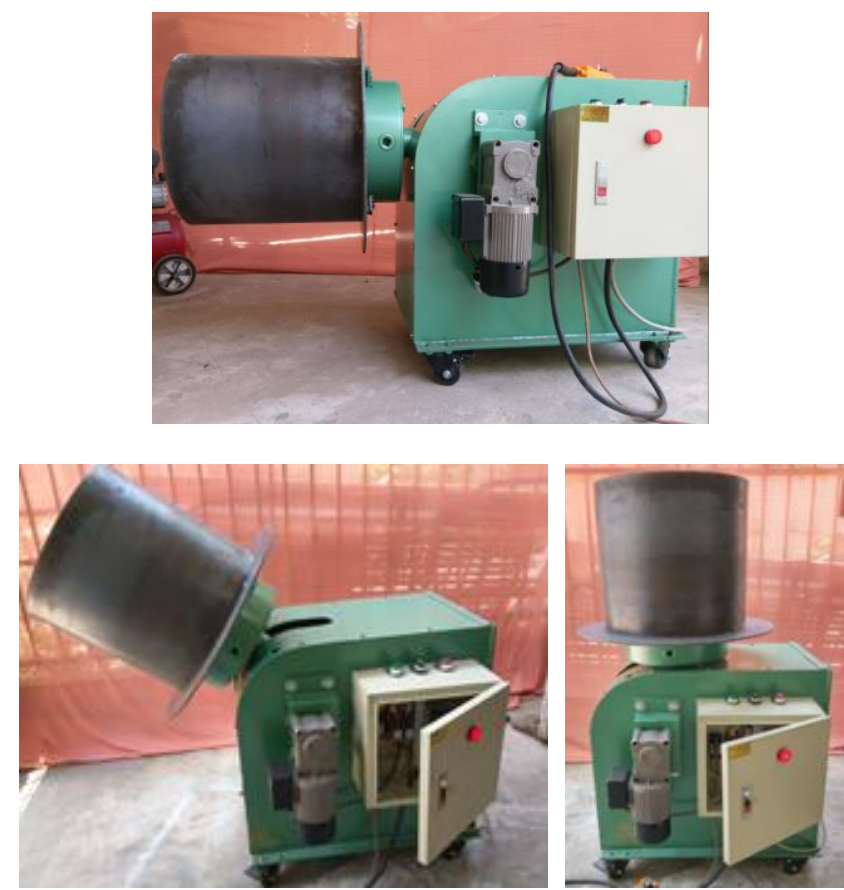

Figure 9. Working angle of the device

After machining the main parts of the equipment, proceed to assembl y to obtain the fixture structure as shown in Figure 7 and Figure 8. After the assembly is finished, details can be attached at various angles, showing the certainty of the experimental model, shown in Figure 9.

\subsection{Experimental operation}

a) Welding flange - tube

Preparing is the first step. Use a metal brush or grinder and clean down to bare metal before striking an arc. Make sure your work clamp connects to clean metal, too. Any electrical impedance will affect wire feeding performance. To ensure strong welds on thicker metal, bevel the joint to ensure the weld fully penetrates to the base metal. This is especially important for butt joints.

Horizontal position: Because of the effects of gravity, the gun work angle must be dropped slightly by 0 to 15 degrees. Without changing the work angle, the filler metal may sag or rollover on the bottom side of the weld joint. The travel angle, whether using a push or a drag technique, generally remains the same as for a weld joint in the flat position, Figure 10(b).

Vertical positions and angle position: The angle welding, both up and down, can be difficult. This makes pre-weld set- 
up very important for making high quality welds. Since you are fighting gravity, consider reducing the voltage and amperage 10 to 15 percent from the settings for the same weld in the flat position.

The vertical down technique helps when welding thin metals because the arc penetrates less due to the faster travel speed. Because vertical down welding helps avoid excessive melt-through, welders sometime place very thin materials in the vertical position even if they can weld them in the flat position. When welding vertical down, begin at the top of a joint and weld down. For thin metal where burn-through is a concern, direct the wire away from the weld puddle. Keep the electrode wire on the leading edge of the weld puddle. A very slight weave may help flatten the weld crown. Such as Figures 10(a) with welding at $45^{\circ}$, the solder metal tends to flow down the welded pile to provide the best weld (weld depth) than the weld at other angles,

In addition, the welding equipment can easily rotate many different positions will be more favorable for the welding of different materials (mass, shape, texture ...).

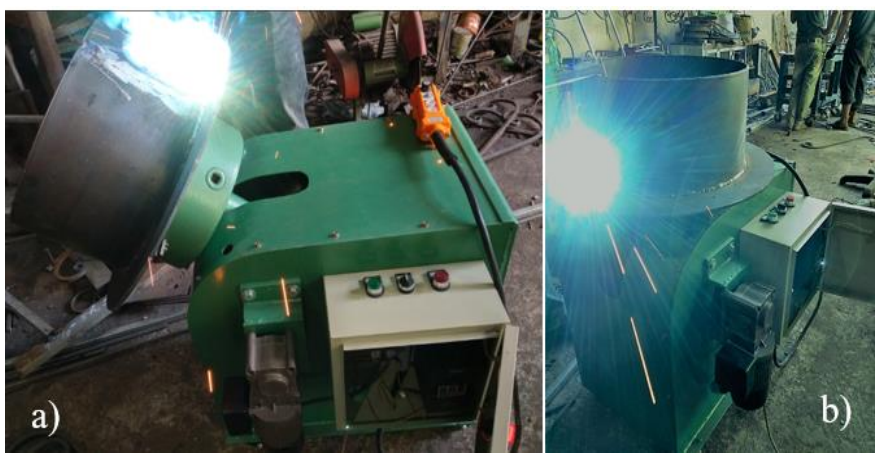

Figure 10. Flange-tube connection welding a. Position $45^{\circ}$; b. Position $90^{\circ}$

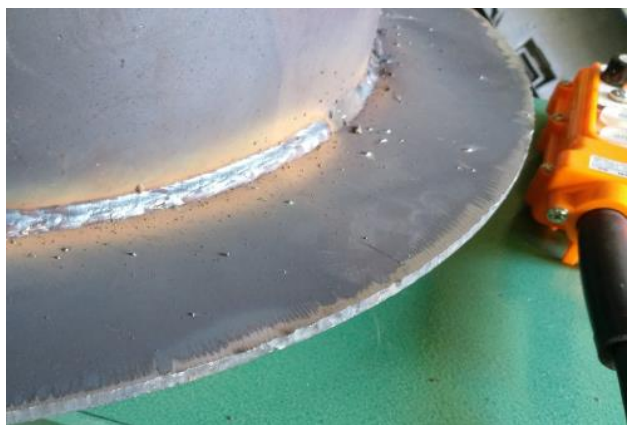

Figure 11. Products after welding

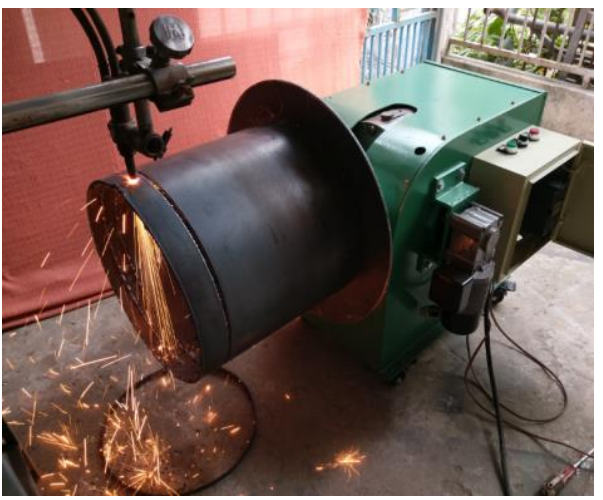

Figure 12. Tube cutting

\section{b) Tube cutting}

The cutting process is illustrated in Figure 10. Basically, a mixture of oxygen and the fuel gas is used to preheat the metal to its 'ignition' temperature which, for steel, is $700^{\circ} \mathrm{C}-900^{\circ} \mathrm{C}$ (bright red heat) but well below its melting point. A jet of pure oxygen is then directed into the preheated area instigating a vigorous exothermic chemical reaction between the oxygen and the metal to form iron oxide or slag. The oxygen jet blows away the slag enabling the jet to pierce through the material and continue to cut through the material.

Equipment working with stepless speed, easy option plan cuts, depending on diameter and thickness details make up the highlight of Rigging in cutting automatically, as Figure 12 shows. With the naked eye, it is possible to observe the product after the automatic cutting has good quality (line cut) as shown in Figure 13. In addition, the cutting speed is more stable than the manual cut.
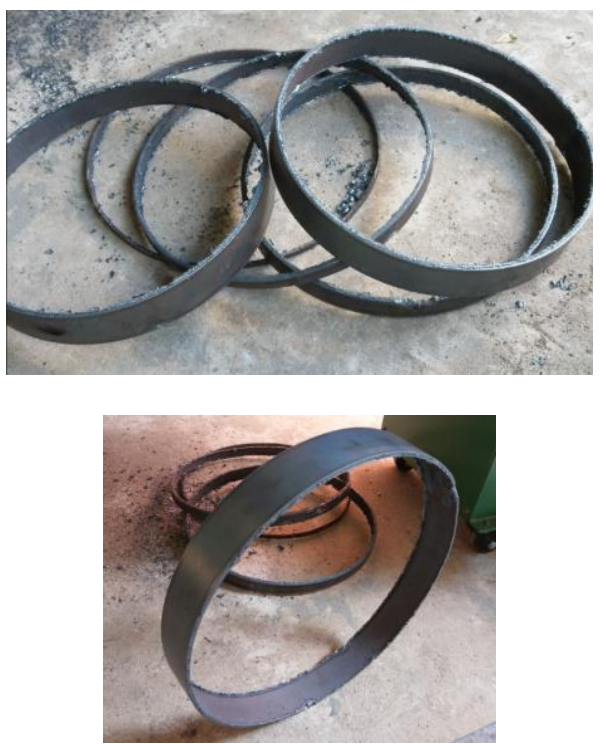

Figure 13. Product after cutting

\section{CONCLUSION}

Through field survey, analysis of the characteristics and scope of application of various types of pipe cutting and cutting parts, the article proposed a new attachment to serve welding, Automatic cutting with medium capacity. After selecting and calculating the geometrical parameters of the main parts of the machine, proceeding with the assembly and assembly has given the experimental model of this new fixture. Highly reliable workmanship, the products created by the support of this device are of high quality, the machine structure can be moved easily on the site, High performance, low cost and easy operation. From there, it can be put into use in the factory or mechanical workshop in the field of welding and cutting tube details with medium capacity.

[1] https://vegatec.com.vn

[2] http://robotec.vn/welding-positioner-300

[3] Nguyen Trong Hiep, Nguyen Van Lam, Design of machine parts, Educational Publishing House, 2007.

[4] http://shoptools.vn/en

[5] https://en.wikipedia.org/wiki/Variable 